\title{
CFTR mediates bicarbonate-dependent activation of miR-125b in preimplantation embryo development
}

Yong Chao Lu ${ }^{1,2,3,6,{ }^{*}}$, Hui Chen ${ }^{1,2, *}$, Kin Lam Fok ${ }^{1,2, *}$, Lai Ling Tsang ${ }^{1,2}$, Mei Kuen Yu ${ }^{1,2}$, Xiao Hu Zhang ${ }^{1,2}$, Jing Chen ${ }^{1,2}$, Xiaohua Jiang ${ }^{1,2,4}$, Yiu Wa Chung ${ }^{1,2}$, Alvin Chun Hang $\mathrm{Ma}^{5}$, Anskar Yu Hung Leung, He Feng Huang ${ }^{1,3}$, Hsiao Chang Chan ${ }^{1,2,4,7}$

${ }^{I}$ The Chinese University of Hong Kong - Zhejiang University Joint Laboratory for Human Reproduction and Related Diseases; ${ }^{2}$ Epithelial Cell Biology Research Center, School of Biomedical Sciences, Faculty of Medicine, The Chinese University of Hong Kong, Hong Kong SAR, China; ${ }^{3}$ Department of Reproductive Endocrinology, Key Laboratory of Reproductive Genetics of Ministry of Education of China, Women's Hospital, School of Medicine, Zhejiang University, Hangzhou, Zhejiang 310006, China; ${ }^{4}$ Key Laboratory for Regenerative Medicine (Jinan University - The Chinese University of Hong Kong), Ministry of Education of China, Guangzhou, Guangdong 510632, China; ${ }^{5}$ Department of Medicine, Li Ka Shing Faculty of Medicine, The University of Hong Kong, Hong Kong SAR, China; ${ }^{6}$ Henan Institute of Population and Family Planning Research, Zhengzhou, Henan 450000, China; ${ }^{7}$ Sichuan University - The Chinese University of Hong Kong Joint Laboratory for Reproductive Medicine, Women and Children's Hospital, Sichuan University, Chengdu, Sichuan 610041, China

Although $\mathrm{HCO}_{3}^{-}$is known to be required for early embryo development, its exact role remains elusive. Here we report that $\mathrm{HCO}_{3}{ }^{-}$acts as an environmental cue in regulating miR-125b expression through CFTR-mediated influx during preimplantation embryo development. The results show that the effect of $\mathrm{HCO}_{3}{ }^{-}$on preimplantation embryo development can be suppressed by interfering the function of a $\mathrm{HCO}_{3}^{-}$-conducting channel, $\mathrm{CFTR}$, by a specific inhibitor or gene knockout. Removal of extracellular $\mathrm{HCO}_{3}{ }^{-}$or inhibition of CFTR reduces miR-125b expression in 2 cell-stage mouse embryos. Knockdown of miR-125b mimics the effect of $\mathrm{HCO}_{3}^{-}$removal and CFTR inhibition, while injection of miR-125b precursor reverses it. Downregulation of miR-125b upregulates p53 cascade in both human and mouse embryos. The activation of miR-125b is shown to be mediated by sAC/PKA-dependent nuclear shuttling of NF- $\mathrm{KB}$. These results have revealed a critical role of CFTR in signal transduction linking the environmental $\mathrm{HCO}_{3}{ }^{-}$to activation of miR-125b during preimplantation embryo development and indicated the importance of ion channels in regulation of miRNAs.

Keywords: embryo; $\mathrm{HCO}_{3}{ }^{-}$; miR-125b; CFTR; sAC

Cell Research (2012) 22:1453-1466. doi:10.1038/cr.2012.88; published online 5 June 2012

\section{Introduction}

After fertilization, mammalian embryos quickly undergo cleavage and differentiation while traveling along the oviduct and making their way to the uterus before implantation. It has been known for decades that female

\footnotetext{
*These three authors contributed equally to this work. Correspondence: Hsiao Chang Chan ${ }^{\mathrm{a}}$, He Feng Huang ${ }^{\mathrm{b}}$

${ }^{\mathrm{a}}$ Tel: +86-852-2609-6839; Fax: +86-852-2603-5022

E-mail: hsiaocchan@cuhk.edu.hk

${ }^{\mathrm{b}}$ E-mail: huanghefg@hotmail.com

Received 20 December 2011; revised 28 March 2012; accepted 9 April 2012; published online 5 June 2012
}

reproductive tract, including the oviduct and uterus, contains high concentrations of $\mathrm{HCO}_{3}^{-}$(up to $90 \mathrm{mM}$ ), which is much higher than that in most other tissues [13]. Thus, preimplantation embryo development occurs in a $\mathrm{HCO}_{3}{ }^{-}$-rich environment. Indeed, our recent study and previous reports have shown that the absence of $\mathrm{HCO}_{3}{ }^{-}$is detrimental beyond two-cell stage. The effect of $\mathrm{HCO}_{3}{ }^{-}$is independent of $\mathrm{CO}_{2}$ and $\mathrm{pH}$, since embryos successfully grew to blastocysts in HEPES-buffered $\mathrm{HCO}_{3}{ }^{-}$medium without $\mathrm{CO}_{2}$ (mouse) [4], but failed to develop beyond two-cell (mouse) $[4,5]$ or morula (rabbit) [6] stage in HEPES-buffered $\mathrm{HCO}_{3}^{-}$-free medium, suggesting that $\mathrm{HCO}_{3}{ }^{-}$is required for early embryo development. However, the question as to how $\mathrm{HCO}_{3}$ 
affects preimplantation embryo development remains unanswered.

MicroRNAs (miRNAs) are small non-coding RNAs that regulate gene expression primarily through base pairing to the 3'UTR of target mRNAs. A number of studies have indicated that miRNAs are essential to embryo development $[7,8]$. In particular, miR-125b, which is known to regulate cell proliferation $[9,10]$ and differentiation [11-13], has been shown to be required for the development of lower organisms, such as Drosophila [14] and zebrafish [15]. The expression of miR-125b is also found in mouse preimplantation embryos although its exact role has not been eluciated [16]. Several proteins, including $\mathrm{p} 53$, have been reported to be the targets of miR-125b and mediate its action in various physiological and pathological events, including neuronal differentiation $[12,17,18]$, immune response $[19,20]$ and cancer [10, 21-23]. Particularly, p53 has been reported to mediate the effect of miR-125b on embryo development [15]. However, compared to the well-demonstrated downstream pathway of miR-125b, the molecular mechanism and signaling pathway in regulating the expression of miR-125b remain largely unknown. Interestingly, recent studies have suggested that the expression of miRNAs are triggered and/or regulated by microenvironments, such as hypoxia and $\mathrm{pH}$ [24-27]. Therefore, it is plausible that the high $\mathrm{HCO}_{3}{ }^{-}$content in the female reproductive tract may act as an environmental cue in regulating miR-125b expression in the transiting preimplantation embryo.

We have previously demonstrated that $\mathrm{HCO}_{3}{ }^{-}$-rich uterine environment triggers sperm capacitation [28], a process by which sperms acquire their fertilizing capacity. The effect of $\mathrm{HCO}_{3}{ }^{-}$in triggering downstream signaling requires CFTR (cystic fibrosis transmembrane conductance regulator), a cAMP-activated anion channel known to conduct $\mathrm{Cl}^{-}[29,30]$ and $\mathrm{HCO}_{3}^{-}[31]$, as the necessary $\mathrm{HCO}_{3}{ }^{-}$transport mechanism, either directly or indirectly $[28,32]$. This suggests that high $\mathrm{HCO}_{3}{ }^{-}$ concentration may act as an environmental stimulus in initiating cellular responses through CFTR-mediated entry. After its entry, $\mathrm{HCO}_{3}^{-}$has been shown to activate the downstream cAMP-dependent pathway in a number of cell types via its sensor, the soluble adenylate cyclase (sAC) [33]. Interestingly, it has been shown that cAMP activation is essential for embryo development [34] and both CFTR and SAC are expressed in preimplantation embryos [5] (Supplementary information, Figures S1 and S2), suggesting their possible involvement in mediating $\mathrm{HCO}_{3}^{-}$-dependent cAMP signaling in preimplantation embryo. Given the recently revealed role of miR-125b in embryo development of lower organisms, we proposed that the high $\mathrm{HCO}_{3}{ }^{-}$content present in the female reproductive tract may exert its effect on embryo development by regulating miR-125b expression via CFTR-mediated cAMP pathway. We undertook the present study to test this hypothesis.

\section{Results}

Involvement of CFTR in $\mathrm{HCO}_{3}^{-}$-dependent preimplantation embryo development

In our previous study, we have compared the effect of $\mathrm{HCO}_{3}^{-}$and $\mathrm{pH}$ on early embryo development and found that $\mathrm{pH}$ is dispensable for development from two-cell stage to blastocyst [5], suggesting that $\mathrm{HCO}_{3}{ }^{-}$ion itself is required for early embryo development. Consistent with our previous observation, the present results showed that the percentage of embryos undergoing the second zygotic division increased in a $\mathrm{HCO}_{3}^{-}$concentrationdependent manner (Figure 1A). Formation of blastocysts also depended on $\mathrm{HCO}_{3}{ }^{-}$concentrations (Supplementary information, Figure S3). The effect of $\mathrm{HCO}_{3}{ }^{-}$on embryo development could be inhibited by a specific inhibitor for CFTR, CFTRinh172 $(10 \mu \mathrm{M})$, which inhibited $\mathrm{HCO}_{3}{ }^{-}$influx in embryos (Supplementary information, Figure S4). As shown in Figure 1B, inhibition of CFTR reduced the cleavage from two-cell stage to four-cell stage by $78 \%$ and completely abolished the formation of blastocysts (Figure 1B), suggesting a critical role of CFTR in mediating the effect of $\mathrm{HCO}_{3}^{-}$on embryo development.

To confirm the inhibition of embryo development did not result from the nonspecific effects of CFTRinh172, we further retrieved embryos that had undergone preimplantation development in vivo from Cftr wild-type and knockout $\left(C f t r^{t m l U n c}\right)$ mice. Since adult $C f t r^{-/-}$mice are rare due to high mortality rate, $\mathrm{Cftr}^{-/-}$embryos could only be obtained through $\mathrm{Cftr}^{+-} \times \mathrm{Cftr}^{+-}$mating, which should, theoretically, yield $25 \% \mathrm{Cftr}^{+/+}, 50 \% \mathrm{Cftr}^{+/-}$and $25 \% \mathrm{Cftr}^{-1-}$ embryos. Examination of the embryos retrieved on $3.5 \mathrm{dpc}$ (days post coitum) showed that only $45 \%$ of the embryos (31 out of 68 ) from $\mathrm{Cftr}^{+/-}$mating formed expanded blastocysts while $79 \%$ of the embryos (60 out of 76) from $\mathrm{Cftr}^{+/+}$mating formed expanded blastocysts (Figure 1C). To confirm that the developmental defects were specific to $\mathrm{Cftr}^{-/-}$embryos, we examined the expression of CFTR in embryos obtained from $\mathrm{Cftr}^{+/}$ $\times \mathrm{Cftr}^{+/-}$crosses. CFTR immunoreactivity should only be observed in wild-type and heterozygous embryos but not in homozygous knockout embryos. Indeed, embryos lacking Cftr immunoreactivity exhibited a remarkable decrease in blastocyst formation rate (Figure 1D), suggesting that CFTR is required for blastocyst formation. Further examination of the tight junction protein, ZO-1, 
A

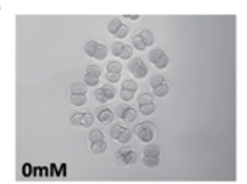$$
\theta_{0}
$$

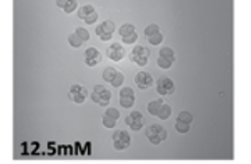

$12.5 \mathrm{~mm}$

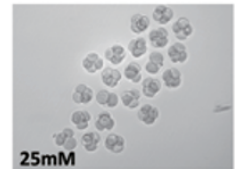

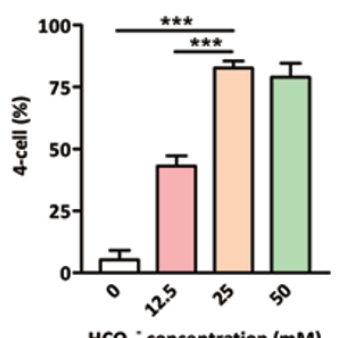

$\mathrm{HCO}_{3}{ }^{\circ}$ concentration (mM)
B
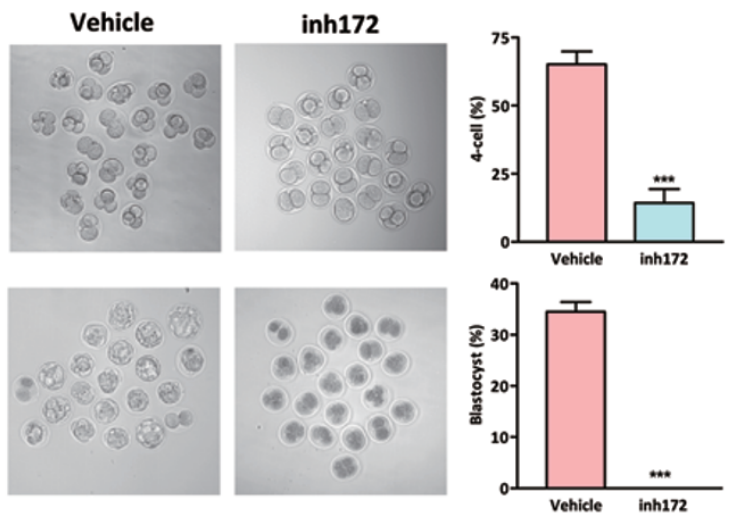

c
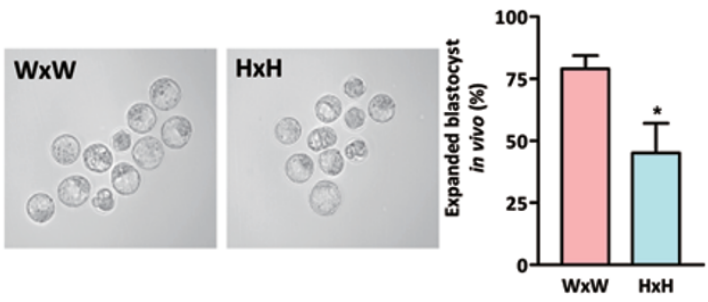

G
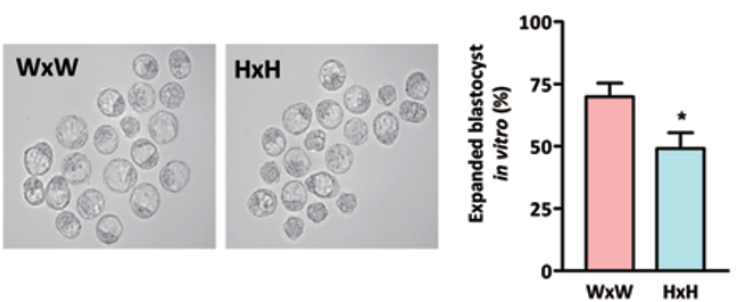

D
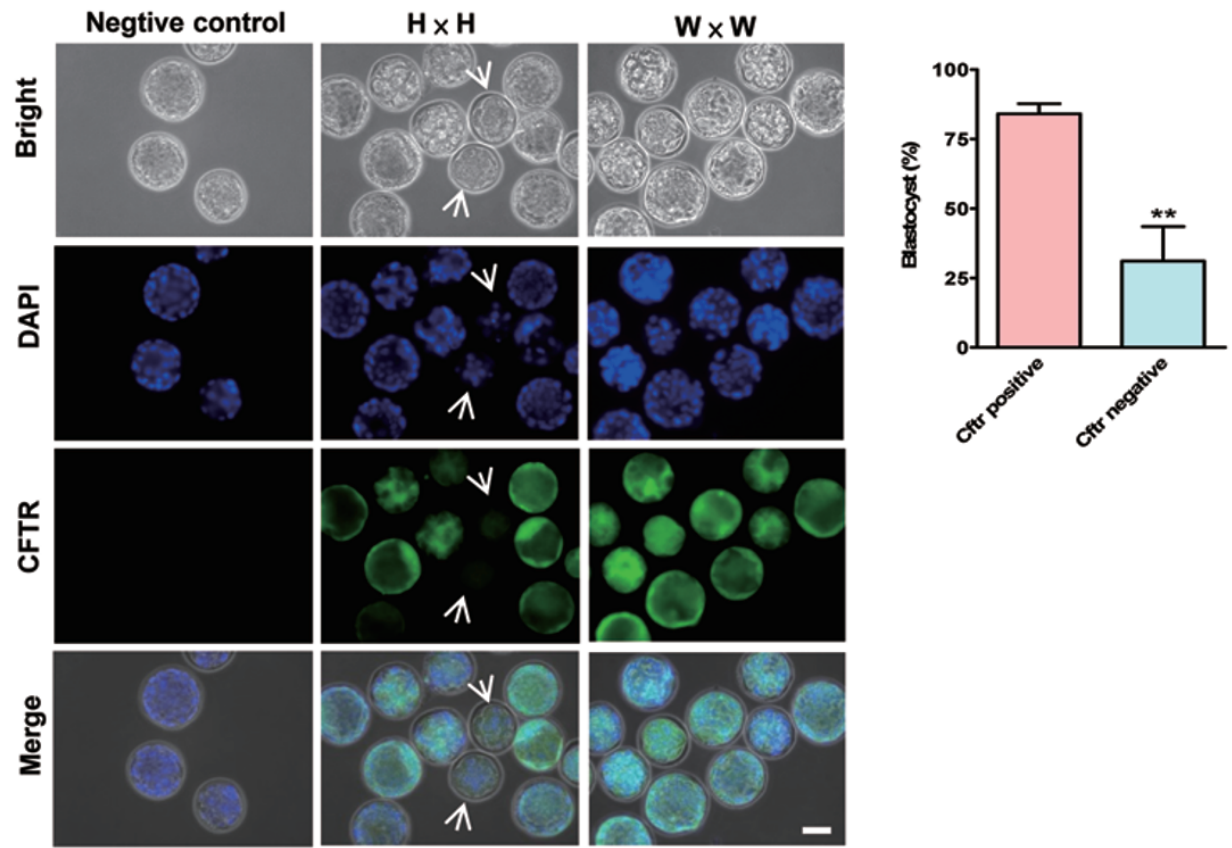

E
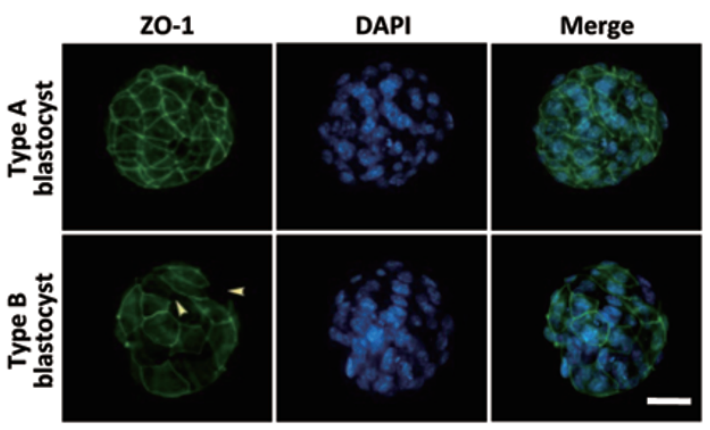

$\mathbf{F}$
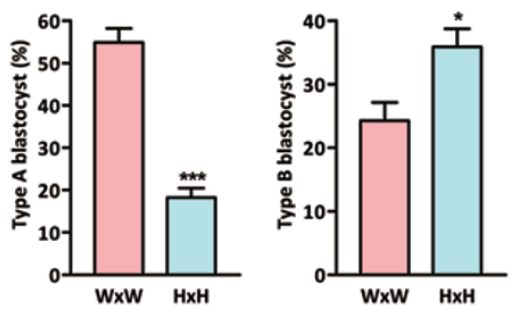
a differentiation marker of preimplantation embryos that involved in morula to blastocyst formation, showed that embryos from $\mathrm{Cftr}^{+/-}$mating had a significantly lower number of blastocysts exhibiting well-organized ZO-1 staining pattern as compared to those obtained from wild type (Figure $1 \mathrm{E}$ and $1 \mathrm{~F}$ ), indicating that normal embryo development requires CFTR.

To exclude possible influence of maternal effect of cystic fibrosis (CF) mice due to impaired CFTR-mediated oviductal $\mathrm{HCO}_{3}{ }^{-}$secretion [5], two-cell embryos were obtained on $1.5 \mathrm{dpc}$ from both $\mathrm{Cftr}^{+/+}$mating and $\mathrm{Cftr}^{+/-}$ mating, then cultured in the bicarbonate-containing medium for $72 \mathrm{~h}$. The result showed that $70 \%$ of the embryos (87 out of 126) collected from $\mathrm{Cftr}^{+/+}$mating, but only $49 \%$ of the embryos (60 out of 122) collected from $\mathrm{Cftr}^{+/-}$mating, developed to expanded blastocyst (Figure $1 \mathrm{G})$. Taken together, these results suggest that CFTR is involved in mediating the effect of extracellular $\mathrm{HCO}_{3}{ }^{-}$ on early-embryo development.

\section{Regulation of miR-125b by CFTR-mediated $\mathrm{HCO}_{3}{ }^{-}$influx in mouse embryo development}

Since miR-125b, which is known to be involved in cellular differentiation and the development of lower organisms [15, 35], is expressed in mouse preimplantation embryo [16], we attempted to test whether $\mathrm{HCO}_{3}{ }^{-}$may act as an environmental cue regulating miR-125b levels and hence embryo development. Using real-time PCR, we first examined the expression profile of miR-125b at different stages of mouse preimplantation embryo development and the results showed a relatively high level of miR-125b at two-cell and four-cell stages, but a significantly lower level in morula and blastocyst (Figure $2 \mathrm{~A}$ ), indicating that miR-125b may be required for early cleavage of embryos, but no longer induced at higher differentiation stage. Strikingly, miR-125b expression in two-cell embryos was significantly reduced by removal of $\mathrm{HCO}_{3}{ }^{-}$and the addition of CFTR inhibitor, CFTRinh172 $(10 \mu \mathrm{M})$ (Figure 2B), suggesting that miR$125 \mathrm{~b}$ expression may be regulated by CFTR-mediated $\mathrm{HCO}_{3}{ }^{-}$entry. This result also suggests that miR-125b may be important in executing the effect of $\mathrm{HCO}_{3}{ }^{-}$on embryo development. To test this, we knocked down endogenous miR-125b by transfecting anti-miR-125b oligo into embryos. The results showed that knockdown of miR-125b significantly decreased the number of fourcell embryos formed compared to anti-miR negative control, which does not target any known miRNAs (Figure $2 \mathrm{C}$ ). The inhibition rate was similar to that obtained using CFTRinh172 (Figure 1B). We also attempted to rescue the impaired embryo development induced by either $\mathrm{HCO}_{3}^{-}$removal or CFTR inhibition by injecting miR-125b precursor (pre-miR-125b) into two-cell embryos. Indeed, the four-cell and blastocyst formation rates were significantly increased by pre-miR-125b, but not by pre-miR-nc control, in $\mathrm{HCO}_{3}{ }^{-}$-free and CFTRinhibited conditions (Figure 2D), further confirming the involvement of miR-125b in CFTR/ $\mathrm{HCO}_{3}{ }^{-}$-regulated embryo development.

\section{Downregulation of miR-125b by blocking $\mathrm{CFTR}-\mathrm{HCO}_{3}$ pathway leads to upregulation of p53 and p 21}

We next sought to identify the downstream effector of miR-125b in mouse embryo. A recent study has found that miR-125b is a novel negative regulator of p53 [15]. Preimplantation embryo development has been shown to require the latency of p53 [36] and increased expression of p53 is associated with poor developmental potential of preimplantation embryos [37]. Therefore, we tested whether downregulation of miR-125b by removal

Figure 1 Involvement of CFTR in $\mathrm{HCO}_{3}{ }^{-}$-dependent preimplantation embryo development. (A) $\mathrm{Effects}$ of $\mathrm{HCO}_{3}{ }^{-}$on preimplantation embryo development. Embryos were cultured in different concentrations of $\mathrm{HCO}_{3}{ }^{-}$. Transition from two-cell

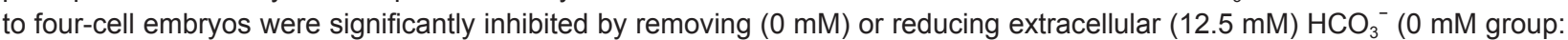
6/108 embryos; 12.5 mM group: 46/106 embryos; 25 mM group: 95/110 embryos; 50 mM group: 83/105 embryos). (B) CFTRinh172 (inh172) significantly reduced four-cell ( $n=4,12 / 85$ embryos) and blastocyst formation (0/85 embryos) in embryo culture containing $25 \mathrm{mM} \mathrm{HCO}_{3}{ }^{-}$compared to the DMSO-treated vehicle control (four-cell: $57 / 88$ embryos; blastocyst: 30/88). (C) Embryos obtained from $\mathrm{Cftr}^{+/-}$mice $(\mathrm{H} \times \mathrm{H})$ on $3.5 \mathrm{dpc}$ have reduced percentage of expanded blastocysts (31/68 embryos) as compared to those obtained from $\mathrm{Cftr}^{+/+}$mice $(\mathrm{W} \times \mathrm{W})\left(60 / 79\right.$ embryos). (D) $\mathrm{Cftr}^{-/-}$embryos, as indicated by lacking CFTR immunoreactivity (arrow), exhibit a remarkable decrease in blastocyst formation rate (5/13 embryos) as compared to CFTR-positive embryos (38/48 embryos). (E) Embryos were categorized into two types according to the developmental stages and ZO-1 fluorescence: type A blastocysts showed continuous and well-organized ZO-1 expression only at the cell junction, while type B blastocyst showed disrupted expression of ZO-1 at the cell junction (arrow head), and diffused localization in cytoplasm. (F) Embryos from $\mathrm{Cftr}^{+/+}$and $\mathrm{Cftr}^{+/-}$mice were classified by ZO-1 expression patterns (green) in blastocyst stages. Nuclei were counterstained by DAPI. Embryos obtained from $\mathrm{Cftr}^{+/-}$mice have a significantly reduced percentage of type A blastocyst. (G) Embryos obtained from $\mathrm{Cftr}^{+-}$mice $(\mathrm{H} \times \mathrm{H})$ on $1.5 \mathrm{dpc}$ have reduced expanded blastocyst formation (60/122 embryos) after in vitro culture for $72 \mathrm{~h}$ as compared to those obtained form $\mathrm{Cftr}^{+/+}$mice $(\mathrm{W} \times \mathrm{W})(87 / 126 \mathrm{embryos})$. Data are presented as mean \pm SEM; one-way ANOVA (A); $t$-test (B-E); ${ }^{*} P<0.05$ and ${ }^{* * *} P<0.001$. Scale bar, $50 \mu \mathrm{m}$. 
A

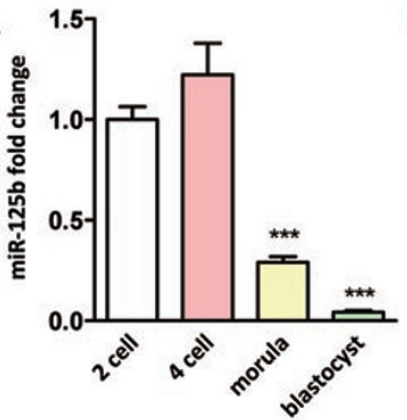

B

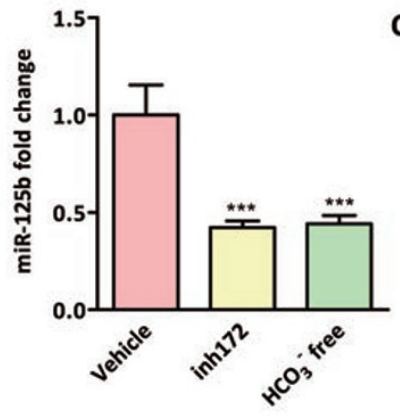

C

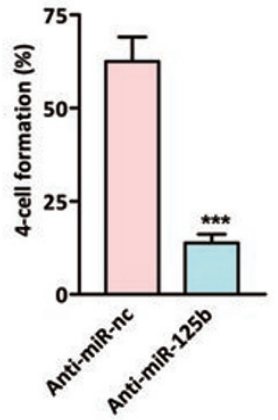

D
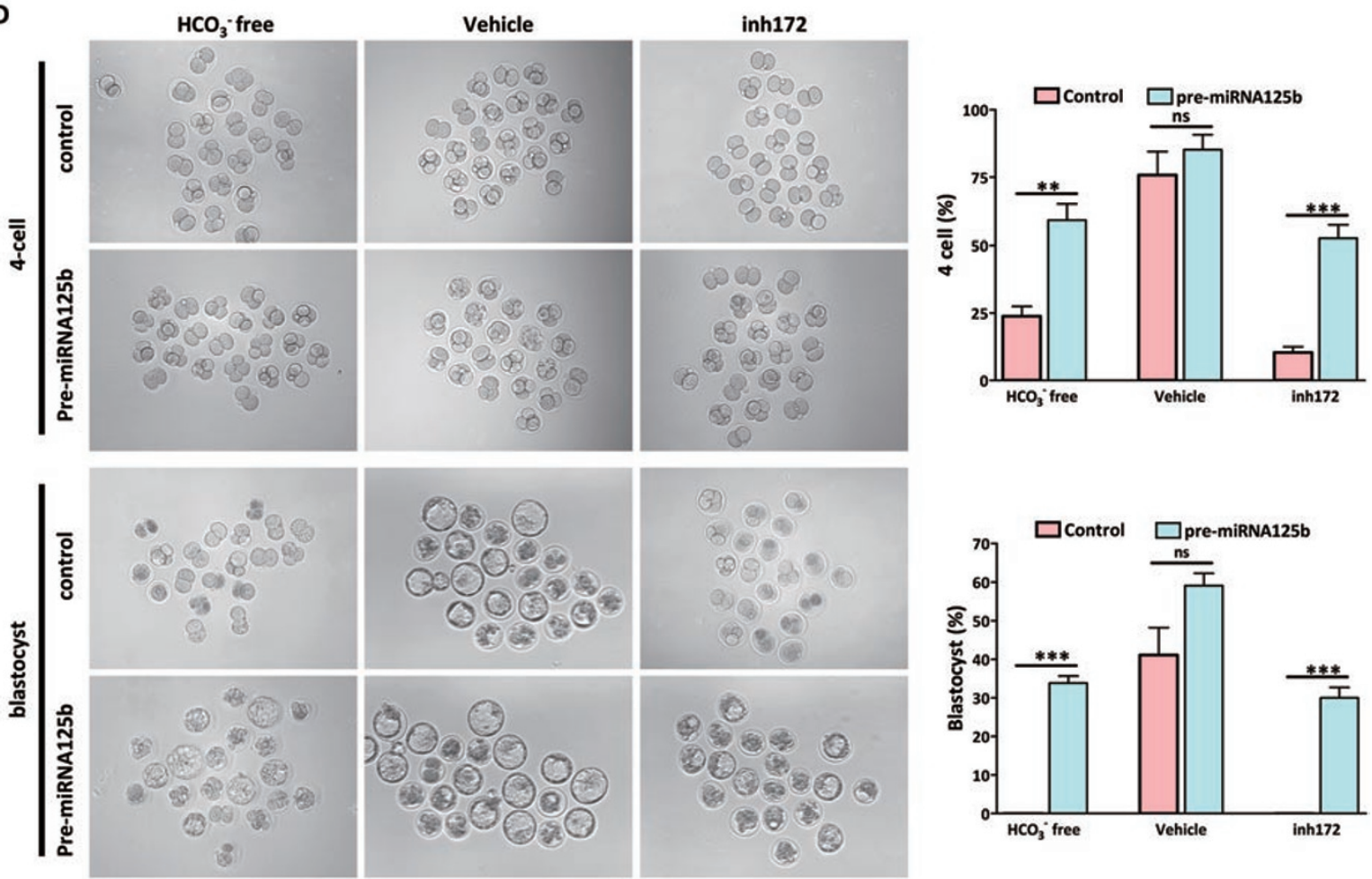

Figure 2 Involvement of miR-125b in CFTR-regulated embryo development. (A) Real-time PCR results showing high miR$125 \mathrm{~b}$ expression in two-cell and four-cell embryos, but significantly reduced in morula and blastocyst stages $(n=4,100$ embryos/group). (B) MiR-125b expression in two-cell embryo was inhibited by CFTRinh172 treatment (compared to DMSOtreated vehicle control) and in $\mathrm{HCO}_{3}{ }^{-}$-free condition ( $n=4,100$ embryos/group). (C) Knockdown of miR-125b inhibited fourcell embryo formation ( $n=4,80$ embryos/group). (D) Impaired four-cell and blastocyst formation by removal of $\mathrm{HCO}_{3}{ }^{-}$and CFTR inhibition was rescued by injection of miR-125b precursor (pre-miR-125b) $(n=3)$; $\mathrm{HCO}_{3}{ }^{-}$free + pre-miR-nc group: four-cell (15/62 embryos), blastocyst (0/62 embryos); $\mathrm{HCO}_{3}{ }^{-}$free + pre-miR-125b group: four-cell (36/61 embryos), blastocyst (21/60 embryos); Vehicle + pre-miR-nc group: four-cell (46/60 embryos), blastocyst (25/60 embryos); Vehicle + pre-miR-125b group: four-cell (55/64 embryos), blastocyst (38/64 embryos); CFTRinh172 + pre-miR-nc group: four-cell (10/60 embryos), blastocyst (0/60 embryos); CFTRinh172 + pre-miR-125b group: four-cell (33/63 embryos), blastocyst (19/63 embryos). Data are presented as mean \pm SEM; One way ANOVA (A, B); $t$-test (C, D); ${ }^{* *} P<0.01$, ${ }^{* * *} P<0.001$, ns - not significant. Scale bar, $50 \mu \mathrm{m}$.

of $\mathrm{HCO}_{3}{ }^{-}$or addition of CFTR inhibitor could lead to the increase in p53 and its downstream target p21 in preimplantation embryos, resulting in impaired development. Immunofluorescence results showed that p53 and p21 signals were enhanced after two-cell embryos were treated with CFTRinh172 or cultured in $\mathrm{HCO}_{3}^{-}$free condition (Figure 3A). The increase in p53 protein level is consistent with the downregulation of miR-125b 
A
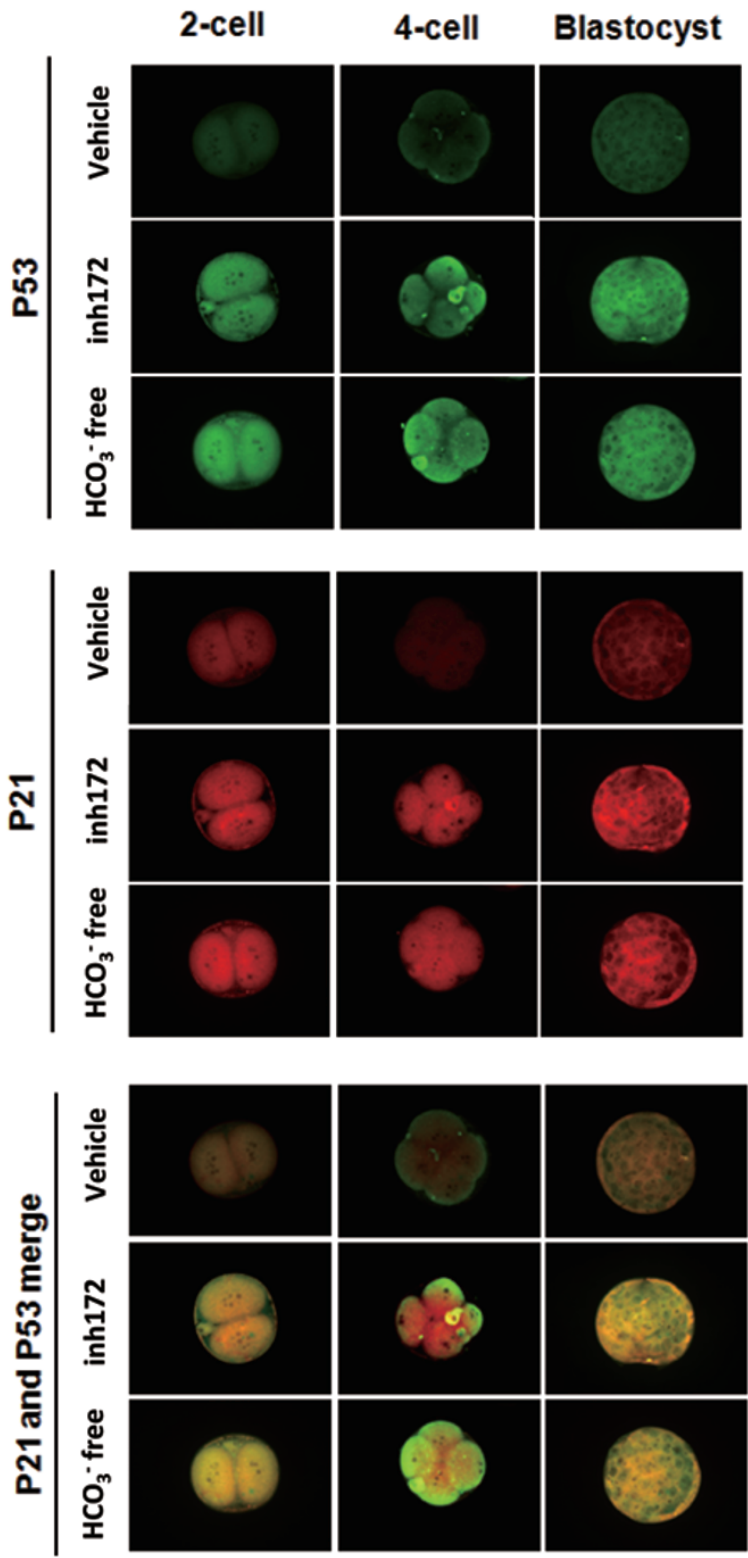

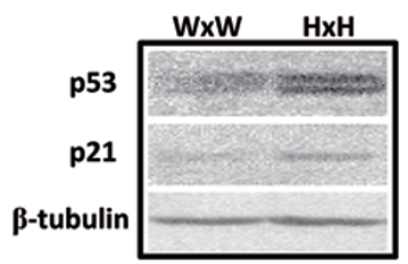

C

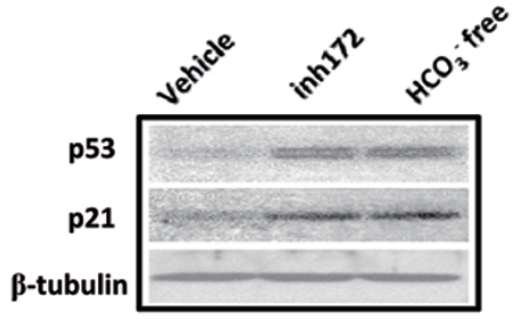

D

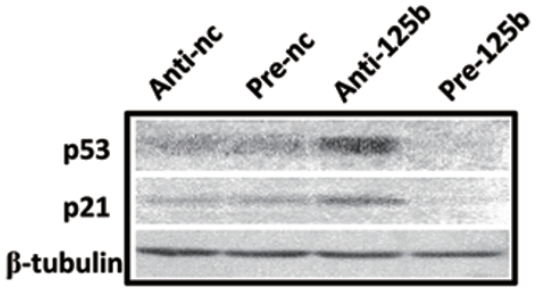

Figure 3 p53 and p21 are the downstream targets of CFTR-HCO${ }_{3}{ }^{-}-\mathrm{miR}-125 \mathrm{~b}$ pathway. (A) Immunofluorescent results showing increased expression of p53 (green) and p21 (red) in $\mathrm{HCO}_{3}{ }^{-}$-free condition or after CFTRinh172 treatment (5-10 embryos/group). (B) Western blot results showing increased expression of p53 and p21 in two-cell embryos from Cftr ${ }^{+-}$mice $(\mathrm{H} \times \mathrm{H})$ compared to those from $\mathrm{Cftr}^{+/+}(\mathrm{W} \times \mathrm{W})$ mice. (C) Western blot results showing upregulation of p53 and p21 by CFTRinh172 or $\mathrm{HCO}_{3}{ }^{-}$-free condition in two-cell embryos. (D) Western blot results showing that transfection of anti-miR-125b oligo leads to increased expression of p53 and p21, while transfection of miR-125b precursor leads to decreased expression of p53 and p21 in two-cell embryos. Scale bar, $50 \mu \mathrm{m}$.

by $\mathrm{HCO}_{3}{ }^{-}$removed or CFTRinh172 treatment in twocell embryos. The upregulation of $\mathrm{p} 53$ and $\mathrm{p} 21$ proteins was confirmed by western blot in embryos collected from CFTR-knockout mice (Figure 3B), treated with CFTRinh172 or under $\mathrm{HCO}_{3}^{-}$-free condition (Figure $3 \mathrm{C})$. We further examined the effect of miR-125b on p53 and p21 expression. We knocked down miR-125b by anti-miR-125b or ectopically overexpressed the precursor (pre-miRNA-125b) in mouse embryos and found that knockdown of miR-125b upregulated p53 and p21 while overexpression of the miR-125b precursor decreased the protein expression of both p53 and p 21 (Figure 3D). Taken together, these results indicate an important role of CFTR-mediated $\mathrm{HCO}_{3}{ }^{-}$entry in 
regulation of embryo development involving miR-125bregulated $\mathrm{p} 53$ cascade.

Removal of $\mathrm{HCO}_{3}{ }^{-}$and inhibition of CFTR suppresses human embryo development with altered miR-125b and $p 53$

We then explored whether the $\mathrm{CFTR} / \mathrm{HCO}_{3}{ }^{-}$ dependent regulation of embryo development involving
miR-125b and p53 is conserved in human embryos. As shown in Figure 4A, removal of $\mathrm{HCO}_{3}{ }^{-}$or treatment with CFTRinh172 significantly inhibited human-embryo development from two-cell stage to four-cell stage and formation of blastocyst. Removal of $\mathrm{HCO}_{3}^{-}$(Figure 4B) or treatment with CFTRinh172 (Figure 4C) also downregulated miR-125b expression in human embryos at two-cell
A
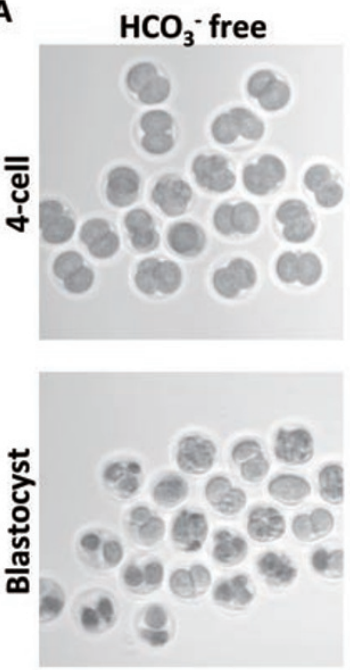

B

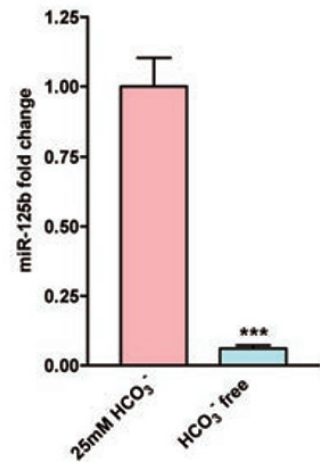

C

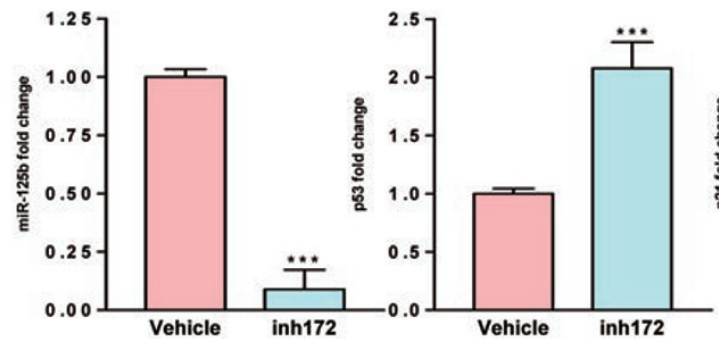

inh172
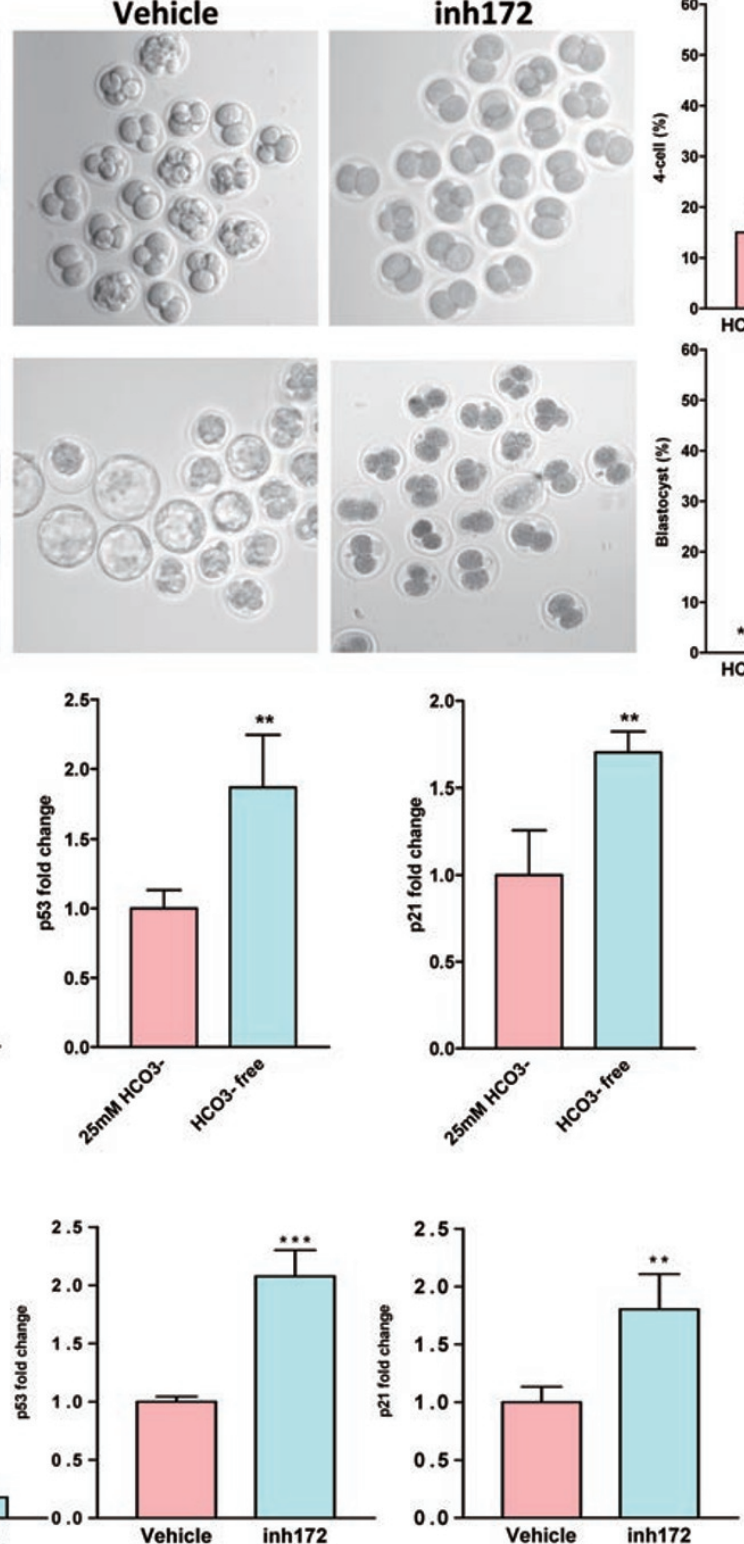
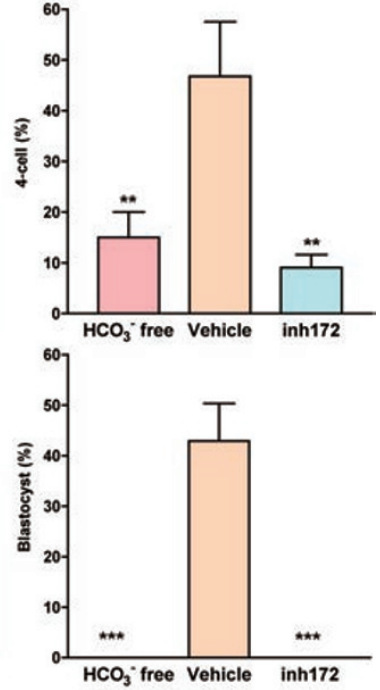

Figure 4 Involvement of CFTR and $\mathrm{HCO}_{3}^{-}$in human embryo development and regulation of miR-125b-p53 cascade. (A) Decreased four-cell and blastocyst formation in $\mathrm{HCO}_{3}{ }^{-}$-free condition or after CFTRinh172 (inh172) treatment $\left(n=3 ; \mathrm{HCO}_{3}^{-}-\right.$ free group: four-cell (9/60 embryos), blasocyst (0/60 embryos); Vehicle group: four-cell (30/63 embryos), blastocyst (27/63 embryos); CFTRinh172 group: four-cell (6/62 embryos), blastocyst (0/62) ). (B, C) Real-time PCR showed expression of miR125b, p53 and p21 under $\mathrm{HCO}_{3}{ }^{-}$-free condition (B) or after CFTRinh172 treatment (C) ( $n=4100$ embryos/group). Inhibition of CFTR or cultured in $\mathrm{HCO}_{3}{ }^{-}$-free condition reduced the expression of miR-125b and increased the expression of p53 and p21. Data are represented as mean \pm SEM; One way ANOVA $(\mathbf{A}) ; t$-test $(\mathbf{B}, \mathbf{C}) ;{ }^{* *} P<0.01,{ }^{* * *} P<0.001$. 
to four-cell stages, while p53 and p21 expression were upregulated, which is consistent with that observed in mouse embryos. These results indicate that the effect of $\mathrm{HCO}_{3}{ }^{-}$on mouse and human-embryo development may be mediated by the same conserved mechanism involving CFTR and miR-125b-p53 cascade.

$\mathrm{HCO}_{3}{ }^{-}$-dependent activation of miR-125b involves $\mathrm{SAC}$ $P K A-N F-\kappa B$ cascade

We have established that $\mathrm{HCO}_{3}^{-}$acts as an environmental cue in regulating miR-125b expression and downstream p53 cascade. Next, we set out to explore the signaling mechanism involved. Since $\mathrm{HCO}_{3}{ }^{-}$is an activator of sAC, the effect of CFTR-mediated $\mathrm{HCO}_{3}^{-}$influx on miR-125b expression and embryo development may be mediated by sAC and its downstream cAMP/PKAdependent pathway $[28,38]$. We therefore tested the involvement of sAC and PKA in $\mathrm{HCO}_{3}{ }^{-}$-dependent embryo development. Two-cell embryos were cultured in TALP medium containing $25 \mathrm{mM} \mathrm{HCO}_{3}^{-}$. Application of sACspecific inhibitor KH7 $(10 \mu \mathrm{M})$ or PKA inhibitor H89 (20 $\mu \mathrm{M})$ in embryo culture drastically inhibited the transformation from two-cell stage to four-cell stage compared to DMSO-treated vehicle control (Figure 5A). In line with the effect on embryo development, miR-125b expression was significantly downregulated by both sAC and PKA inhibitors compared to DMSO-treated vehicle control (Figure 5B). These results suggest the involvement of sAC and its downstream PKA signaling pathway in $\mathrm{HCO}_{3}{ }^{-}$-dependent miR-125b expression and embryo development.

Activation of PKA has been shown to stimulate the transcriptional activity of NF- $\kappa B$ [39]. Interestingly, activation of NF- $\kappa B$ has been observed in early singlecell stage embryo and postulated to be required for the development of mouse embryos beyond the twocell stage [40]. More importantly, NF- $\mathrm{BB}$ can bind to the promoter element of miR-125b and upregulate its expression [20]. Therefore, we proposed that CFTRmediated $\mathrm{HCO}_{3}{ }^{-}$influx activates $\mathrm{sAC}$, which in turns triggers PKA-dependent NF- $\kappa \mathrm{B}$ activation, leading to upregulation of miR-125b expression. To test this, we studied the activation of NF- $\mathrm{KB}$ by examining the $\mathrm{NF}-\kappa \mathrm{B}$ p 65 shuttle between cytoplasm and nucleus using immunofluorescence staining. As shown in Figure $5 \mathrm{C}, \mathrm{NF}-\kappa \mathrm{B}$ p 65 translocated to the nucleus in twocell embryos in the presence of $25 \mathrm{mM} \mathrm{HCO}_{3}{ }^{-}$. The translocation was inhibited by removal of $\mathrm{HCO}_{3}{ }^{-}$or treatment with CFTRinh172, sAC inhibitor KH7, PKA inhibitor $\mathrm{H} 89$ (Figure $5 \mathrm{C}$ ) and $\mathrm{NF}-\mathrm{\kappa B}$ inhibitor AK $\beta \mathrm{BA}$ $(10 \mu \mathrm{M})$ (Figure 5D). These results suggest that the translocation or activation of NF- $\mathrm{KB}$ in mouse em- bryos depends on $\mathrm{HCO}_{3}{ }^{-}$and CFTR, which are known to activate sAC/cAMP/PKA pathway. Blocking NF$\kappa \mathrm{B}$ activation by its inhibitor, $\mathrm{AK} \beta \mathrm{BA}$, also resulted in downregulation of miR-125b in two-cell embryos in the presence of $25 \mathrm{mM} \mathrm{HCO}_{3}{ }^{-}$as demonstrated by real-time PCR (Figure 5E). These results indicate that the CFTR/ $\mathrm{HCO}_{3}{ }^{-}$-dependent activation of miR-125b is mediated by sAC/PKA-dependent NF- $\kappa$ B activation.

\section{Discussion}

Although it has been reported that miRNAs undergo dynamic changes during preimplantation embryo development [41], the exact nature of the environmental cues that lead to such alterations in embryos and the underlying mechanism have not been elucidated. The present study has demonstrated for the first time that extracellular $\mathrm{HCO}_{3}^{-}$can regulate embryonic miR-125b through CFTR-mediated entry and subsequent sAC, PKA and $\mathrm{NF}-\mathrm{kB}$ activation, which is important for preimplantation embryo development (Figure 6). This provides the first explanation to the long-observed dependency of early embryo development on $\mathrm{HCO}_{3}{ }^{-}$and suggests that $\mathrm{HCO}_{3}{ }^{-}$acts as an environmental cue for the regulation of miRNAs during early embryo development.

MiR-125b appears to be dynamically regulated during preimplantation embryo development. The expression levels of miR-125b in two-cell and four-cell embryos were significantly higher than that in morula and blastocyst stage (Figure 2A), which coincides with the transit of embryo from oviduct (high bicarbonate concentration) to the uterus (lower bicarbonate concentration) [42]. This suggested that the window for $\mathrm{HCO}_{3}{ }^{-}$ dependent miR-125b activation occurs from fertilization to four-cell stage but not in subsequent stages. The $\mathrm{HCO}_{3}{ }^{-}$-dependent miR-125b activation is physiologically important for early embryo development by targeting p53 and its downstream target $\mathrm{p} 21$. It has been previously demonstrated that the latency of p53 is required for normal preimplantation embryo development [43]. Stress-induced upregulation of p53 has been shown to result in developmental arrest of preimplantation embryo [44]. The latency of p53 in preimplantation embryo is well-documented to be maintained by autocrine stimulation through PI3K/Akt/Mdm2 pathway [43]. In this study, we have demonstrated an alternative pathway regulating the latency of p53 through $\mathrm{HCO}_{3}^{-} / \mathrm{CFTR}$-dependent miR-125b activation. This p53 latency appears to be dynamically regulated, as shown by the expression profile of miR-125b in embryos of different stages (Figure $2 \mathrm{~A})$. The presently demonstrated epigenetic regulation of p53 latency may provide a fine-tuning mechanism 
A
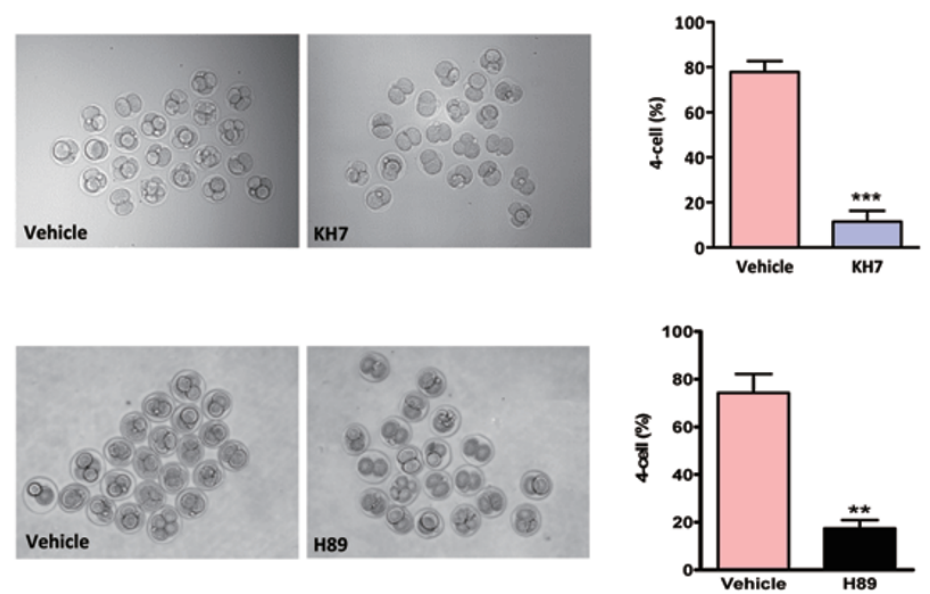

B

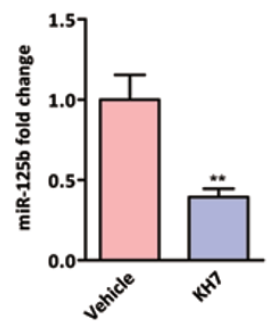

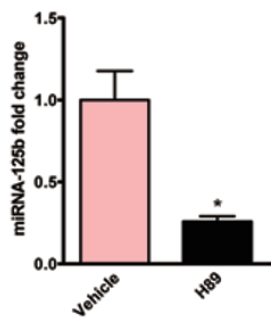
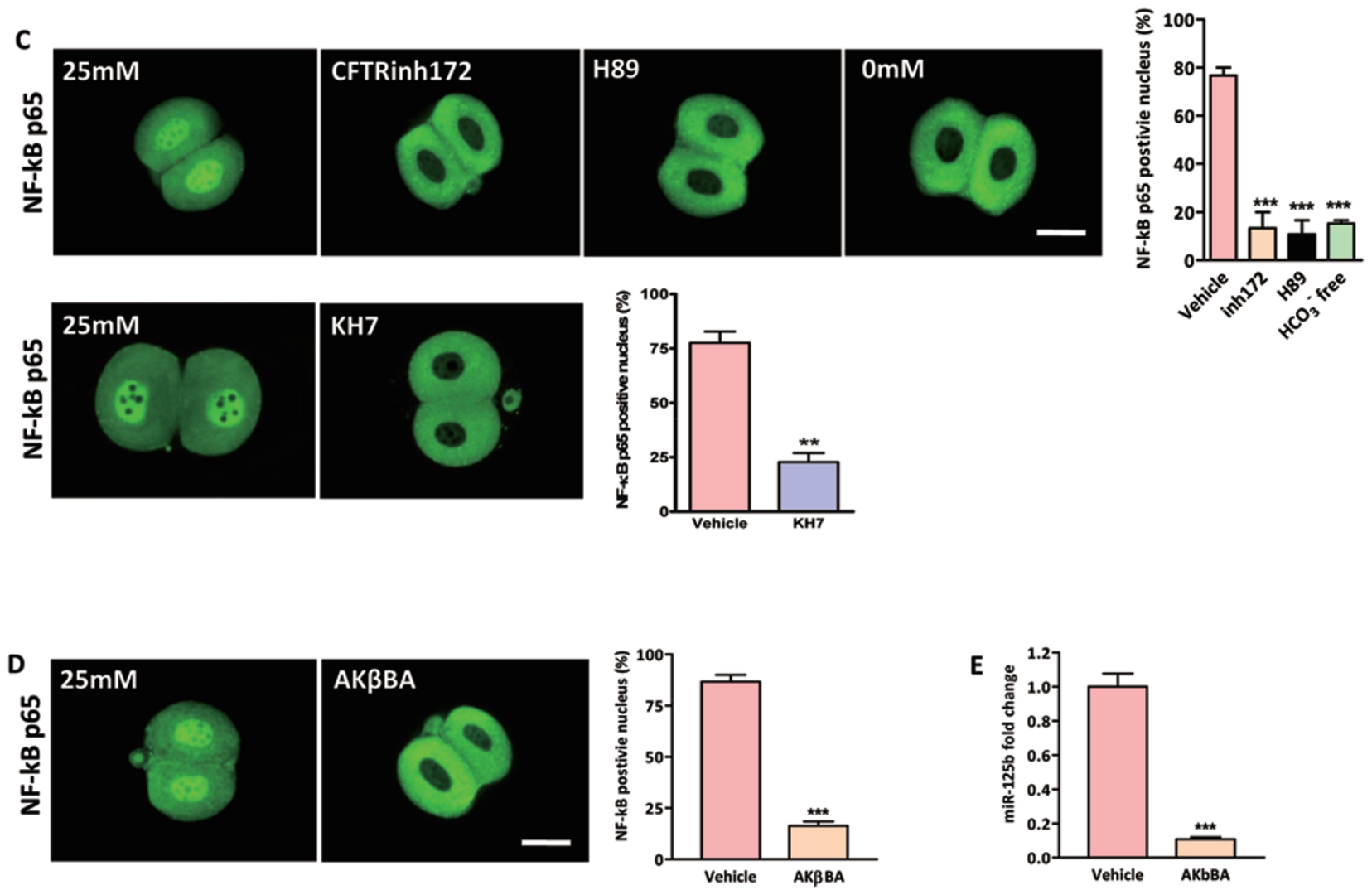

Figure 5 Involvement of sAC/PKA/NF- $\mathrm{kB}$ cascade in $\mathrm{HCO}_{3}{ }^{-}$-dependent miR-125b activation. (A) Involvement of sAC in the $\mathrm{HCO}_{3}{ }^{-}$-dependent embryo development. $\mathrm{HCO}_{3}{ }^{-}$-dependent four-cell formation was significantly inhibited by addition of sAC inhibitor KH7 (10/86 embryos) and PKA inhibitor H89 (14/80 embryos) compared to DMSO-treated vehicle control (60/77 embryos (KH7); 56/75 embryos (H89)). (B) miR-125b expression in two-cell embryo was inhibited by both $\mathrm{KH} 7$ and $\mathrm{H} 89$ treatments compared to DMSO-treated vehicle control. (C, D) Immunofluorescent staining showing the localization of NF- $\mathrm{B}$ p65 subunit in both nucleus and cytoplasm in $25 \mathrm{mM} \mathrm{HCO}_{3}{ }^{-}$condition (23/30 embryos). $\mathrm{HCO}_{3}{ }^{-}$-free (3/20 embryos), $10 \mu \mathrm{M}$ CFTRinh172 (4/28 embryos), $10 \mu \mathrm{M} \mathrm{KH7} \mathrm{(7/30} \mathrm{embryos),} 20 \mu \mathrm{M}$ PKA inhibitor H89 (3/27 embryos) (C) and $10 \mu \mathrm{M}$ NF-кB

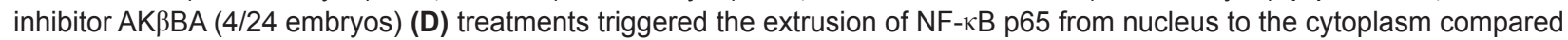
to DMSO-treated vehicle control group (20/26 embryos (KH7); 26/30 embryos (AK $\beta B A)$ ); statistics showing $\mathrm{HCO}_{3}^{-}$-free condition, CFTRinh172, H89 and AKBBA significantly reduced the percentage of p65 nuclear positive embryos. (E) Real-time PCR results showing that AKBBA inhibited miR-125b expression in two-cell embryos ( $n=4100$ embryos/group). Data are represented as mean \pm SEM. One way ANOVA (C); $t$-test (A, B, D); ${ }^{* *} P<0.01,{ }^{* *} P<0.001$. Scale bar, $50 \mu \mathrm{m}$. 


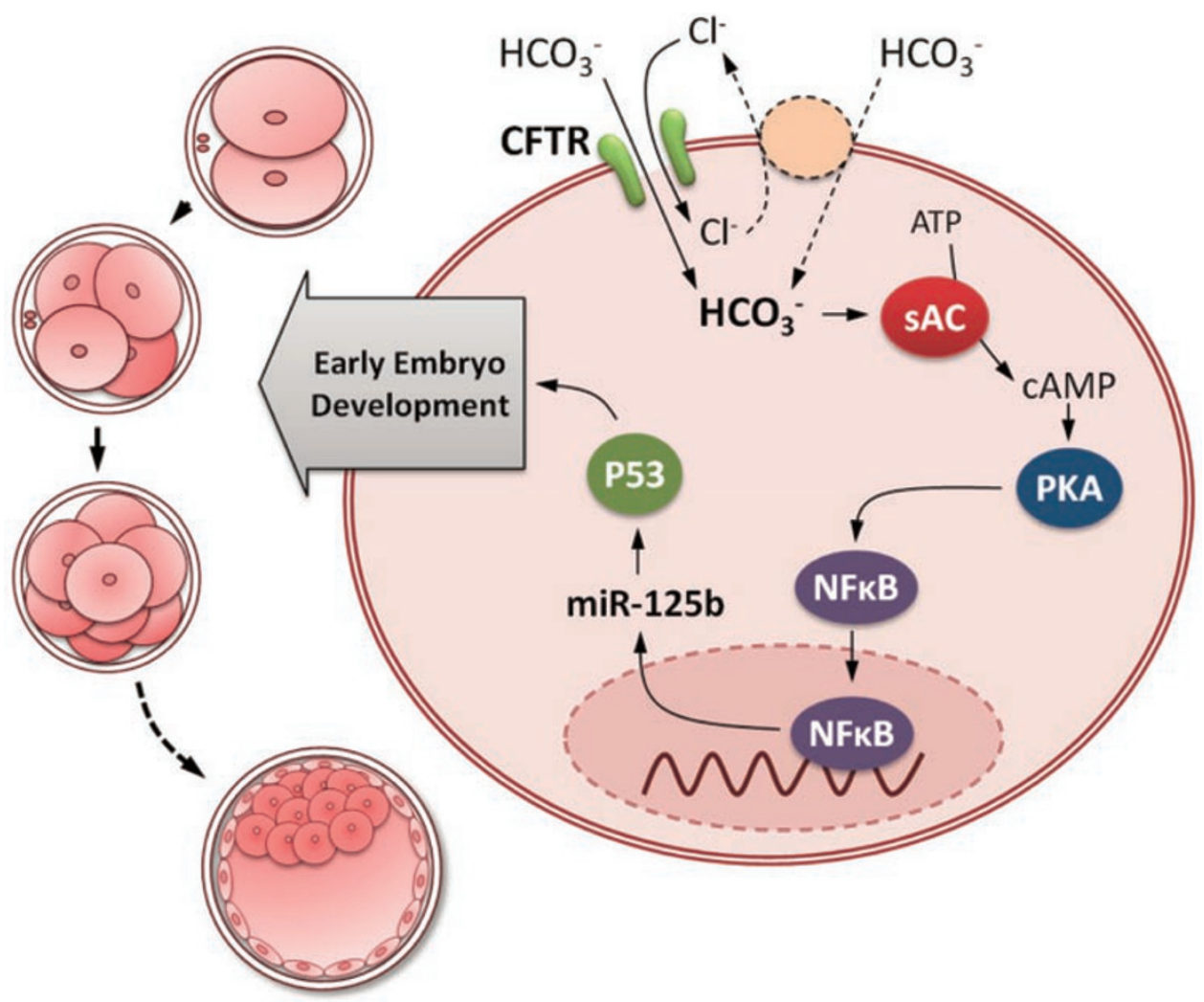

Figure 6 Working model for the regulation of early embryo development by $\mathrm{CFTR} / \mathrm{HCO}_{3}{ }^{-}$-dependent activation of miR-125b. CFTR mediates the influx of $\mathrm{HCO}_{3}{ }^{-}$ion directly and/or indirectly by cooperating with an anion exchanger. The influx of $\mathrm{HCO}_{3}{ }^{-}$ activates SAC, an enzyme that converts ATP to CAMP, which in turn activates PKA, triggering the nuclear shuttle of NF- $\mathrm{BB}$ a transcription factor known to regulate the expression of miR-125b. Induction of miR-125b expression by CFTR-mediated $\mathrm{HCO}_{3}{ }^{-}$influx maintains the dormancy of $\mathrm{p} 53$, which is required for early embryo development.

for embryo development on top of the well-established $\mathrm{PI} 3 \mathrm{~K} / \mathrm{Akt} / \mathrm{Mdm} 2$ autocrine feedback loop.

The observed inhibitory effect of $\mathrm{HCO}_{3}{ }^{-}$deprivation, CFTR inhibitor and sAC inhibitor on two-cell to fourcell transition is interesting, since two-cell stage is the time for mouse zygotic genome activation (ZGA), failure of which results in two-cell arrest. ZGA is the global reprogramming of gene expression in early embryos, which transforms the genome from transcription quiescence at fertilization to robust transcriptional activity [45]. The initiation of transcription requires the activation of a variety of transcription factors. It has been reported that the cAMP-PKA pathway is involved in ZGA and also the subsequent embryo development [46, 47]. A recent report has also demonstrated the increase in DNA binding activity of NF- $\kappa \mathrm{B}$ in bovine embryo, suggesting that NF$\kappa \mathrm{B}$ might be involved in ZGA [48]. In the present study, we have shown that $\mathrm{HCO}_{3}{ }^{-}$activates cAMP-PKA and $\mathrm{NF}-\kappa \mathrm{B}$ through CFTR and sAC, suggesting that $\mathrm{HCO}_{3}{ }^{-}$ may be involved in the regulation of ZGA via the CFTR/ sAC/PKA/NF- $\mathrm{KB}$ pathway, apart from its involvement in the epigenetic regulation of $\mathrm{p} 53$ latency.

While the present results show that CFTR inhibitor can almost completely retard the embryo development in vitro, some $\mathrm{Cftr}^{-/-}$embryos, if not all, from $\mathrm{Cftr}^{+-} \times$ $\mathrm{Cftr}^{+/-}$mating can survive and develop to birth. If CFTR is required for preimplantaion embryo development, how can some CFTR-deficient embryos survive and undergo further development? Ben-Chetrit et al.[49] have suggested that the maternal CFTR mRNA stored in the heterozygous mother's oocytes can be translated into protein and rescue the $\mathrm{Cftr}^{-/-}$embryos from developmental block in early embryo stage. In fact, some maternal derived protein can persist until expanded blastocyst stage and have epigenetic effect on the early embryo development [50]. The possible presence of maternal CFTR mRNA in $\mathrm{Cftr}^{-/-}$embryos may partially explain the survival of some homozygous CFTR-deficient mice. Similar argument can be used to explain the survival of CF patients. It should be noted that the $\triangle F 508$ CFTR mutation most commonly seen in CF patients affects the processing of the protein, but retains residual channel 
function on the plasma membrane, which may still support some CF embryo development. The survival of $\mathrm{CF}$ patients through development may present a false picture since the incidence of preimplantation loss of CF embryos in humans is unknown. According to our long-term animal breeding data, the percentage of offspring with $\mathrm{Cftr}^{-/}$genotype from $\mathrm{Cftr}^{+/-}$mice mating is only 0.23/4, significantly less than the expected Mandelian ratio 1/4 (Supplementary information, Table S1), suggesting developmental disadvantage of $\mathrm{Cftr}^{-/}$embryos. Thus, poor or delayed embryo development due to defective CFTR, which may miss the implantation window, may contribute to the reduced fertility in CF.

The present study has demonstrated a critical role of CFTR in mediating the regulatory effect of $\mathrm{HCO}_{3}{ }^{-}$on embryo development. The altered miR-125b levels in response to changes in $\mathrm{HCO}_{3}{ }^{-}$concentrations in embryos and the demonstrated ability of CFTR in transporting $\mathrm{HCO}_{3}{ }^{-}$[28] suggest an important role of CFTR, as an ion channel, in linking the extracellular environment, such as the $\mathrm{HCO}_{3}{ }^{-}$-rich oviductal/uterine fluid, to the intracellular response, such as the changes in miR-125b and its downstream targets p53 and p21, for early embryo development. More importantly, CFTR is expressed in many different tissues, including the epithelium [51], endothelium [52], heart [53], neurons [54] and germ cells [55]. On the other hand, $\mathrm{HCO}_{3}^{-}$is also abundant in extracellular fluid and acts as a bioactive molecule, with sAC as its sensor, which is also known to be evolutionally conserved and widely expressed in different tissues [56]. The conserved wide distribution of CFTR and SAC in various cell types suggests that the presently demonstrated $\mathrm{CFTR}-\mathrm{HCO}_{3}^{-}$dependent signaling pathway may have implications in other cellular processes far beyond embryo development. Of interest, CFTR expression and its channel activity are also found to be regulated by various environmental factors, such as hypoxia [57], ion concentrations [58, 59] and mechanical stimulation [60], suggesting its potential in sensing a wide spectrum of environmental changes and converting these changes into epigenetic changes, such as miRNA alteration, in the cell under various physiological and pathological conditions.

\section{Materials and Methods}

\section{Mouse embryos}

Mice were obtained from the laboratory animal service center (LASEC) of the Chinese University of Hong Kong (CUHK). $C f t r^{\text {tmlUnc }}$ (CFTR knock-out) mice, with a neomycin selection cassette inserted into exon 10 at sequences corresponding to codon 489 of the encoded CFTR protein [61], were obtained from the Jackson Laboratory and maintained in LASEC of CUHK. To obtain preimplantation embryos, female ICR mice of 8-10 weeks old were superovulated by intraperitoneal injections of 10 IU pregnant mares' serum gonadotropin (PMSG), followed by 10 IU human chorionic gonadotropin (hCG) and caged with male mice at $48 \mathrm{~h}$ post PMSG. $\mathrm{Cftr}^{\text {tmlUnc }}(+/-)$ or $C f t r(+/+)$ mice were mated without superovulation. Successful mating was confirmed by the appearance of vaginal plug. Two-cell embryos were flushed out from the oviducts or uteri with TALP-HEPES medium and cultured in TALP medium [62] in $5 \% \mathrm{CO}_{2} / 95 \%$ air at $37{ }^{\circ} \mathrm{C}$. Unless otherwise specified, all embryos were cultured in the presence of $25 \mathrm{mM}$ $\mathrm{HCO}_{3}{ }^{-}$. For development assessment, embryos were cultured for $72 \mathrm{~h}$ till expanded blastocyst stage and stages of development were monitored and recorded at different time points. For analysis of miR-125b, p53, p21, embryos were collected after various treatments for $6 \mathrm{~h}$. For NF- $\mathrm{BB}$ analysis, embryos were treated for 10 and $30 \mathrm{~min}$. All animal handling protocols were approved by the Animal Research Ethics Committee of the Chinese University of Hong Kong.

\section{Human embryo collection and manipulation}

Human embryos were obtained by intracytoplasmic sperm injection (ICSI) and stored in liquid nitrogen in Henan Institute of Population and Family Planning Research. Written consents were obtained from patients who got pregnant after the assisted reproduction program and agreed to donate the spare frozen embryos to research. Human embryos were cultured in TALP medium and treated in the same conditions as that for the mouse embryos. All procedures were approved by the Ethics Committee of Henan Institute of Population and Family Planning Research.

\section{Anti-miR-125b and pre-miR-125b transfection}

Zona pellucida of the embryos was dissolved in TALP medium $(\mathrm{pH} 2.35)$. The embryos were washed in normal TALP-HEPES medium for three times and transfected with $5 \mu \mathrm{L}$ Lipofectamine 2000 reagent (Invitrogen, Carlsbad, CA, USA) and $2 \mu \mathrm{L}$ of $50 \mathrm{nM}$ anti-miRNA negative control, anti-miR-125b inhibitor (AM17000, Ambion, Austin, TX, USA), pre-miRNA negative control or premiR-125b (AM17100, Ambion, Austin, TX, USA) as described. The embryos were collected $12 \mathrm{~h}$ post-transfection for RT-PCR or western blot analysis.

\section{Pre-miR-125b microinjection}

Pre-miRNA negative control or pre-miR-125b was dissolved in RNase-free water. Each blastomere of two-cell embryos was injected with 50 fmol of pre-miRNA solution at the two-cell stage using the micromanipulation system. Formation rate of four-cell and blastocyst was accessed 12 and $48 \mathrm{~h}$ after injection.

\section{Immunofluorescent staining}

Embryos were fixed in $4 \%$ paraformaldehyde, blocked with $10 \%$ goat serum and incubated at $4{ }^{\circ} \mathrm{C}$ overnight with primary antibodies: rabbitanti-CFTR-polyclonal antibody (1:500, Alomone labs, Jerusalem, Israel); rabbit anti-sAC polyclonal antibody (1:500, a gift from Dr Ping Bo Huang); rabbit anti-ZO-1 polyclonal antibody (1:500, Zymed, San Francisco, CA, USA); goat anti-p53 polyclonal antibody (1:100, Santa Cruz Biotechnology, Santa Cruz, CA, USA); mouse anti-p21 monoclonal antibody (1:100, Cell Signaling Technology, Danvers, MA, USA); and rabbit antiNF-кB p65 (1:200, Cell Signaling Technology, Danvers, MA, USA). After intensive wash with PBS with $0.1 \%$ Triton X-100 
(PBST), embryos were incubated with Alexa 488 goat anti-rabbit IgG (1:500), Alexa 568 goat anti-mouse IgG (1:500) or Alexa 488 rabbit anti-goat $\operatorname{IgG}(1: 500)$ for $30 \mathrm{~min}$, followed by nuclei counterstaining with DAPI (1:1 000) for $20 \mathrm{~min}$.

\section{RT-PCR and real-time PCR}

Embryos were washed in PBS, frozen in liquid nitrogen and stored at $-80{ }^{\circ} \mathrm{C}$. Total RNA extraction and reverse transcription (RT) were performed using Cells-to-cDNA ${ }^{\mathrm{TM}}$ II Kit as described (Ambion, Austin, TX, USA). Negative control was performed with no reverse transcriptase added. Expression of Cftr and sAC were determined by RT-PCR using the following primers: mCftr F 5'CAT CTT TGG TGT TTC CTA TGA TG-3' and mCftr R 5'-GTA AGG TCT CAG TTA GAA TTG AA-3'; msAC F 5'-CAT GAG CAA GGA ATG GTG GTA CTC A-3' and msAC R 5'-AAG GGT TAC CTT GCC TGA TAC AAT T-3'; mGapdh F 5'-GAC CAC AGT CCA TGA CAT CAC TGC-3' and mGapdh R 5'-GCT GTT GAA GTC GCA GGA GAC AAC-3'. Real time PCR for mir-125b was carried out with microRNA assay kit (Assay ID: 000449, Applied Biosystems, Carlsbad, CA, USA). snoRNA202 was used as miRNA control (Assay ID: 001232, Applied Biosystems, Carlsbad, CA, USA).

\section{Western blot analysis}

Embryos (200-400 embryos/group) were pooled, lysed by loading buffer. Proteins were separated by SDS-PAGE and transferred to nitrocellulose membrane. After blocking with $4 \%$ milk, the blots were probed overnight at $4{ }^{\circ} \mathrm{C}$ with the following antibodies: antiCFTR (1:500, Alexis); anti-sAC (1:500); anti- $\beta$-tubulin (1:2 000); anti-p53 (1:200); anti-p21 (1:200) (all from Santa Cruz Biotechnolgy, Santa Cruz, CA, USA). The signal was detected with HRPconjugated secondary antibody and visualized using ECL Western Blot Detection Reagent (GE Healthcare).

\section{Statistical analysis}

Results were presented as mean \pm SEM. Student's unpaired $t$-test was used for two-group comparison. One-way ANOVA followed by Tukey's post-hoc test was used when comparing three or more groups. A probability of $P<0.05$ was considered to be statistically significant.

\section{Acknowledgments}

This work was supported by the National Basic Research Program of China (973 program; 2012CB944900), the National Natural Science Foundation of China (30973209), the Focused Investment Scheme and Li Ka Shing Institute of Health Sciences of The Chinese University of Hong Kong, Fundamental Research Funds for the Central Universities (Jinan University) and the Morningside Foundation. We would like to thank Dr YC Ruan for her help in the artwork.

\section{References}

1 Maas DH, Storey BT, Mastroianni L Jr. Hydrogen ion and carbon dioxide content of the oviductal fluid of the rhesus monkey (Macaca mulatta). Fertil Steril 1977; 28:981-985.

2 Murdoch RN, White IG. The influence of the female genital tract on the metabolism of rabbit spermatozoa. I. Direct effect of tubal and uterine fluids, bicarbonate, and other factors. Aust J Biol Sci 1968; 21:961-972.

3 Vishwakarma P. The $\mathrm{pH}$ and bicarbonate-ion content of the oviduct and uterine fluids. Fertil Steril 1962; 13:481-485.

4 Ali J, Whitten WK, Shelton JN. Effect of culture systems on mouse early embryo development. Hum Reprod 1993; 8:11101114.

5 Chen $\mathrm{MH}$, Chen $\mathrm{H}$, Zhou Z, et al. Involvement of CFTR in oviductal HCO3- secretion and its effect on soluble adenylate cyclase-dependent early embryo development. Hum Reprod 2010; 25:1744-1754.

6 Kane MT. Bicarbonate requirements for culture of one-cell rabbit ova to blastocysts. Biol Reprod 1975; 12:552-555.

7 Cui XS, Shen XH, Kim NH. Dicer1 expression in preimplantation mouse embryos: Involvement of Oct3/4 transcription at the blastocyst stage. Biochem Biophys Res Commun 2007; 352:231-236.

8 Tang F, Kaneda M, O'Carroll D, et al. Maternal microRNAs are essential for mouse zygotic development. Genes Dev 2007; 21:644-648.

9 Shi L, Zhang J, Pan T, et al. MiR-125b is critical for the suppression of human U251 glioma stem cell proliferation. Brain Res 2010; 1312:120-126.

10 Liang L, Wong CM, Ying Q, et al. MicroRNA-125b suppressesed human liver cancer cell proliferation and metastasis by directly targeting oncogene LIN28B2. Hepatology 2010; 52:1731-1740.

11 Malumbres R, Sarosiek KA, Cubedo E, et al. Differentiation stage-specific expression of microRNAs in B lymphocytes and diffuse large B-cell lymphomas. Blood 2009; 113:37543764.

12 Le MT, Xie H, Zhou B, et al. MicroRNA-125b promotes neuronal differentiation in human cells by repressing multiple targets. Mol Cell Biol 2009; 29:5290-5305.

13 Mizuno Y, Yagi K, Tokuzawa Y, et al. miR-125b inhibits osteoblastic differentiation by down-regulation of cell proliferation. Biochem Biophys Res Commun 2008; 368:267-272.

14 Sempere LF, Sokol NS, Dubrovsky EB, Berger EM, Ambros V. Temporal regulation of microRNA expression in Drosophila melanogaster mediated by hormonal signals and broadComplex gene activity. Dev Biol 2003; 259:9-18.

15 Le MT, Teh C, Shyh-Chang N, et al. MicroRNA-125b is a novel negative regulator of p53. Genes Dev 2009; 23:862876.

16 Byrne MJ, Warner CM. MicroRNA expression in preimplantation mouse embryos from Ped gene positive compared to Ped gene negative mice. J Assist Reprod Genet 2008; 25:205214.

17 Ferretti E, De Smaele E, Miele E, et al. Concerted microRNA control of Hedgehog signalling in cerebellar neuronal progenitor and tumour cells. EMBO J 2008; 27:2616-2627.

$18 \mathrm{Wu}$ L, Belasco JG. Micro-RNA regulation of the mammalian lin-28 gene during neuronal differentiation of embryonal carcinoma cells. Mol Cell Biol 2005; 25:9198-9208.

19 Tili E, Michaille JJ, Cimino A, et al. Modulation of miR-155 and miR-125b levels following lipopolysaccharide/TNF-alpha stimulation and their possible roles in regulating the response to endotoxin shock. J Immunol 2007; 179:5082-5089.

20 Zhou R, Hu G, Liu J, et al. NF-kappaB p65-dependent tran- 
sactivation of miRNA genes following Cryptosporidium parvum infection stimulates epithelial cell immune responses. PLoS Pathog 2009; 5:e1000681.

21 Shi XB, Xue L, Ma AH, et al. miR-125b promotes growth of prostate cancer xenograft tumor through targeting pro-apoptotic genes. Prostate 2011; 71:538-549.

22 Guan Y, Yao H, Zheng Z, Qiu G, Sun K. MiR-125b targets BCL3 and suppresses ovarian cancer proliferation. Int J Cancer 2011; 128:2274-2283.

23 Bousquet M, Harris MH, Zhou B, Lodish HF. MicroRNA miR-125b causes leukemia. Proc Natl Acad Sci USA 2010; 107:21558-21563.

24 Herranz H, Cohen SM. MicroRNAs and gene regulatory networks: managing the impact of noise in biological systems. Genes Dev 2010; 24:1339-1344.

25 Leung AK, Sharp PA. MicroRNA functions in stress responses. Mol Cell 2010; 40:205-215.

26 Kulshreshtha R, Ferracin M, Wojcik SE, et al. A microRNA signature of hypoxia. Mol Cell Biol 2007; 27:1859-1867.

27 O’Connell RM, Taganov KD, Boldin MP, Cheng G, Baltimore D. MicroRNA-155 is induced during the macrophage inflammatory response. Proc Natl Acad Sci USA 2007; 104:16041609.

28 Xu WM, Shi QX, Chen WY, et al. Cystic fibrosis transmembrane conductance regulator is vital to sperm fertilizing capacity and male fertility. Proc Natl Acad Sci USA 2007; 104:9816-9821.

29 Rich DP, Anderson MP, Gregory RJ, et al. Expression of cystic fibrosis transmembrane conductance regulator corrects defective chloride channel regulation in cystic fibrosis airway epithelial cells. Nature 1990; 347:358-363.

30 Anderson MP, Gregory RJ, Thompson S, et al. Demonstration that CFTR is a chloride channel by alteration of its anion selectivity. Science 1991; 253:202-205.

31 Poulsen JH, Fischer H, Illek B, Machen TE. Bicarbonate conductance and $\mathrm{pH}$ regulatory capability of cystic fibrosis transmembrane conductance regulator. Proc Natl Acad Sci USA 1994; 91:5340-5344.

32 Chen WY, Xu WM, Chen $\mathrm{ZH}$, et al. Cl- is required for HCO3entry necessary for sperm capacitation in guinea pig: involvement of a Cl-/HCO3- exchanger (SLC26A3) and CFTR. Biol Reprod 2009; 80:115-123.

33 Baudouin-Legros M, Hamdaoui N, Borot F, et al. Control of basal CFTR gene expression by bicarbonate-sensitive adenylyl cyclase in human pulmonary cells. Cell Physiol Biochem 2008; 21:75-86.

$34 \mathrm{Yu} \mathrm{A}$, Zhang Z, Bi Q, et al. Regulation of cAMP on the first mitotic cell cycle of mouse embryos. Mol Reprod Dev 2008; 75:489-495.

35 Caygill EE, Johnston LA. Temporal regulation of metamorphic processes in Drosophila by the let-7 and miR-125 heterochronic microRNAs. Curr Biol 2008; 18:943-950.

36 Jin XL, Chandrakanthan V, Morgan HD, O’Neill C. Preimplantation embryo development in the mouse requires the latency of TRP53 expression, which is induced by a ligandactivated PI3 kinase/AKT/MDM2-mediated signaling pathway. Biol Reprod 2009; 81:234-242.

37 Li A, Chandrakanthan V, Chami O, O'Neill C. Culture of zygotes increases TRP53 [corrected] expression in B6 mouse embryos, which reduces embryo viability. Biol Reprod 2007; 76:362-367.

$38 \mathrm{Xu}$ WM, Chen J, Chen H, et al. Defective CFTR-Dependent CREB Activation Results in Impaired Spermatogenesis and Azoospermia. PLoS One 2011; 6:e19120.

39 Zhong H, Voll RE, Ghosh S. Phosphorylation of NF-kappa B p65 by PKA stimulates transcriptional activity by promoting a novel bivalent interaction with the coactivator CBP/p300. Mol Cell 1998; 1:661-671.

40 Nishikimi A, Mukai J, Yamada M. Nuclear translocation of nuclear factor kappa B in early 1-cell mouse embryos. Biol Reprod 1999; 60:1536-1541.

41 Yang Y, Bai W, Zhang L, et al. Determination of microRNAs in mouse preimplantation embryos by microarray. Dev Dyn 2008; 237:2315-2327.

42 Zhao Y, Baltz JM. Bicarbonate/chloride exchange and intracellular $\mathrm{pH}$ throughout preimplantation mouse embryo development. Am J Physiol 1996; 271:C1512-C1520.

43 Jin XL, Chandrakanthan V, Morgan HD, O’Neill C. Preimplantation embryo development in the mouse requires the latency of TRP53 expression, which is induced by a ligandactivated PI3 kinase/AKT/MDM2-mediated signaling pathway. Biol Reprod 2009; 80:286-294.

44 Kawamura Y, Uchijima Y, Horike N, et al. Sirt3 protects in vitro-fertilized mouse preimplantation embryos against oxidative stress-induced p53-mediated developmental arrest. J Clin Invest 2010; 120:2817-2828.

45 Bultman SJ, Gebuhr TC, Pan H, et al. Maternal BRG1 regulates zygotic genome activation in the mouse. Genes Dev 2006; 20:1744-1754.

46 Schwartz DA, Schultz RM. Zygotic gene activation in the mouse embryo: involvement of cyclic adenosine monophosphate-dependent protein kinase and appearance of an AP-1like activity. Mol Reprod Dev 1992; 32:209-216.

47 Bleckmann SC, Blendy JA, Rudolph D, et al. Activating transcription factor 1 and CREB are important for cell survival during early mouse development. Mol Cell Biol 2002; 22:1919-1925.

48 Paciolla M, Boni R, Fusco F, et al. Nuclear factor-kappa-Binhibitor alpha (NFKBIA) is a developmental marker of NF$\kappa \mathrm{B} / \mathrm{p} 65$ activation during in vitro oocyte maturation and early embryogenesis. Hum Reprod 2011; 26:1191-1201.

49 Ben-Chetrit A, Antenos M, Jurisicova A, et al. Expression of cystic fibrosis transmembrane conductance regulator during early human embryo development. Mol Hum Reprod 2002; 8:758-764.

50 Haegel H, Larue L, Ohsugi M, et al. Lack of beta-catenin affects mouse development at gastrulation. Development 1995; 121:3529-3537.

51 Denning GM, Ostedgaard LS, Cheng SH, Smith AE, Welsh MJ. Localization of cystic fibrosis transmembrane conductance regulator in chloride secretory epithelia. J Clin Invest 1992; 89:339-349.

52 Tousson A, Van Tine BA, Naren AP, Shaw GM, Schwiebert LM. Characterization of CFTR expression and chloride channel activity in human endothelia. Am J Physiol 1998; 275:C1555-C1564.

53 Levesque PC, Hart PJ, Hume JR, Kenyon JL, Horowitz B. Expression of cystic fibrosis transmembrane regulator $\mathrm{Cl}^{-}$ 
channels in heart. Circ Res 1992; 71:1002-1007.

54 Mulberg AE, Resta LP, Wiedner EB, et al. Expression and localization of the cystic fibrosis transmembrane conductance regulator mRNA and its protein in rat brain. $J$ Clin Invest 1995; 96:646-652.

55 Gong XD, Li JC, Cheung KH, et al. Expression of the cystic fibrosis transmembrane conductance regulator in rat spermatids: implication for the site of action of antispermatogenic agents. Mol Hum Reprod 2001; 7:705-713.

56 Chen Y, Cann MJ, Litvin TN, et al. Soluble adenylyl cyclase as an evolutionarily conserved bicarbonate sensor. Science 2000; 289:625-628.

57 Zheng W, Kuhlicke J, Jackel K, et al. Hypoxia inducible factor-1 (HIF-1)-mediated repression of cystic fibrosis transmembrane conductance regulator (CFTR) in the intestinal epithelium. FASEB J 2009; 23:204-213.
58 Park HW, Nam JH, Kim JY, et al. Dynamic regulation of CFTR bicarbonate permeability by $\left[\mathrm{Cl}^{-}\right] \mathrm{i}$ and its role in pancreatic bicarbonate secretion. Gastroenterology 2010; 139:620-631.

59 Wang Y, Lam CS, Wu F, et al. Regulation of CFTR channels by $\mathrm{HCO}(3)--$ sensitive soluble adenylyl cyclase in human airway epithelial cells. Am J Physiol Cell Physiol 2005; 289:C1145-C1151.

60 Zhang WK, Wang D, Duan Y, et al. Mechanosensitive gating of CFTR. Nat Cell Biol 2010; 12:507-512.

61 Snouwaert JN, Brigman KK, Latour AM, et al. An animal model for cystic fibrosis made by gene targeting. Science 1992; 257:1083-1088.

62 Bavister BD, Leibfried ML, Lieberman G. Development of preimplantation embryos of the golden hamster in a defined culture medium. Biol Reprod 1983; 28:235-247.

(Supplementary information is linked to the online version of the paper on the Cell Research website) 